\title{
Efeito do congelamento na determinação do número mais provável de coliformes em carne moída
}

\section{Effect of freezing in determining the most likely number of coliforms in minced meat}

Vinícius de Paula Castania ${ }^{1}$, Naiá Carla Marchi de Rezende-Lagoํㅜㄹ Patrícia Gelli Feres de Marchi $^{2}$, Lidianne Assis Silva², Karolayne Negreiros Justo ${ }^{2}$, Jennifer Vital², Guaraicy Maia², Cassio Toledo Messias ${ }^{2 *}$

\section{RESUMO}

Por ser um país com economia agropecuária predominante, o Brasil destaca-se no cenário mundial como um grande produtor de carne bovina. Recentemente a imagem de país foi manchada devido as investigações decorrentes a várias fraude encontradas nos produtos cárneos bovinos que seriam exportados. Os produtos oferecidos a população nem sempre estão adequados para consumo, isso, devido à falta de comprometimento de alguns profissionais do Serviço de Inspeção Federal encarregado de avaliar e regulamentar as normas relacionadas à qualidade físico-químico-microbiológica dos alimentos. Ainda com o desconhecimento da população em armazenar e conservar adequadamente os produtos cárneos expostos a venda e na residência da população, pode piorar a qualidade do alimento. Assim, esse trabalho teve como objetivo verificar a qualidade da carne moída vendida em açougues de Ribeirão Preto/SP, bem como a influência do congelamento na população de coliformes presentes nessa carne. Para isso, as amostras serão analisadas no dia da compra e após permanecerem sob congelamento por quatro semanas.

Palavras-chave: Alimentação; Microrganismos; Intoxicação.

\begin{abstract}
As a country with a predominant agricultural economy, Brazil stands out on the world stage as a major beef producer. Recently, the country's image was tarnished due to investigations arising from various fraud found in beef products that would be exported. The products offered to the population are not always suitable for consumption, due to the lack of commitment of some professionals from the Federal Inspection Service in charge of evaluating and regulating standards related to the physical-chemical-microbiological quality of food. Even with the population's lack of knowledge in properly storing and conserving meat products exposed for sale and in the population's residence, the quality of the food can worsen. Thus, this work aimed to verify the quality of ground beef sold in butchers in Ribeirão Preto/SP, as well as the influence of freezing on the population of coliforms present in this meat. For this, the samples will be analyzed on the day of purchase and after remaining under freezing for four weeks.
\end{abstract}

Keywords: Food; Microorganisms; Intoxication.

\footnotetext{
${ }^{1}$ Centro Universitário Moura Lacerda, São Paulo, Brasil.

${ }^{2}$ Universidade Federal do Acre (UFAC), Acre, Brasil.

*E-mail: ctoldeomessias@gmail.com
} 


\section{INTRODUÇÃO}

Atualmente, o Brasil se destaca quando o assunto é carne bovina. Durante décadas o número de rebanhos vem aumentando e, por consequência desse aumento, o consumo, a produção e a exportação colocaram nosso país como primeiro lugar no ranking mundial. Em 2015, o Brasil tinha o maior rebanho bovino com 215,2 milhões de cabeças e era o segundo maior exportador de carne in natura, com 1,4 milhão de toneladas (ABIEC 2018; IBGE 2018).

Em 2016, o Brasil conquistou o título de país com maior rebanho mundial, com 218,23 milhões de cabeças (crescimento de 1,4\% referente ao ano anterior). Números como os de exportação dos anos mais recentes demonstram que o rebanho bovino segue aumentando. Em 2017, a exportação chegou a 1,5 milhão de toneladas (crescimento de $10 \%$ referente ao ano anterior); e nos dois primeiros meses do ano de 2018, houve um crescimento de 17\% referente aos mesmos meses de 2017 (ABIEC 2018; IBGE 2018).

A carne tem um papel muito importante como veículo de transmissão de microrganismos, uma vez que sua composição química é excelente como meio de cultura. Os fatores intrínsecos que favorecem o desenvolvimento de tais microrganismos são a alta atividade de água, $\mathrm{pH}$ favorável e o fornecimento de nutrientes como substâncias nitrogenadas, minerais e fatores de crescimento. Fatores extrínsecos como temperatura, umidade do ambiente e embalagem também contribuem para a proliferação microbiana (FRANCO e LANDGRAF, 2008; FORSYTHE, 2013; TEIXEIRA et al., 2017).

A carne moída é muito apreciada pelos consumidores devido ao seu preço baixo, grande praticidade e produção rápida. A alta atividade da água e a sua grande disponibilidade de nutrientes, a torna um alimento suscetível ao crescimento microbiano. Desta maneira, a exposição a contaminantes durante o processamento ou armazenamento pode facilitar a disseminação de patógenos, principalmente se forem realizados sob temperaturas (BEZERRA et al, 2019; OLIVEIRA et al., 2019;)

Os principais perigos microbiológicos encontrados na carne são, em sua maioria, bactérias, tais como, Escherichia coli, Salmonella, Yersinia e Trichinella spiralis em suínos (ICMSF, 2015).

A contaminação da carne provém do próprio animal (alimentação, fator de estresse), do manejo durante o abate e do manuseio dessa carne (condições higiênicosanitárias), assim como os utensílios utilizados no processo (FRANCO e LANDGRAF, 
2008). A microbiota presente na carne é influenciada também pelos microrganismos comensais ou patogênicos do manipulador do alimento. Essa microbiota é, sem dúvida, de grande diversidade (SILVA-JÚNIOR et al., 2018).

O objetivo dessa pesquisa é verificar o número mais provável de coliformes totais presentes na carne moída após ser submetida à um período de congelamento.

\section{MATERIAIS E MÉTODOS}

Para a realização dessa pesquisa, foram colhidas 20 amostras de carne moída (patinho) pesando aproximadamente 200 gramas cada uma, obtidas em diferentes açougues de Ribeirão Preto/SP, no período de outubro de 2019 a fevereiro de 2020. Elas foram devidamente identificadas com o local da compra, horário e data.

As amostras foram transportadas desde sua compra dentro de uma bolsa isotérmica contendo compressa de gelo até o Laboratório de Microbiologia de Alimentos do Centro Universitário Moura Lacerda da cidade de Ribeirão Preto, SP.

Para iniciar a análise microbiológica, foi necessário fazer um processo de diluição da amostra. Desta forma, $25 \mathrm{~g}$ de carne moída foram adicionados a $225 \mathrm{ml}$ de solução salina peptonada a $0,1 \%$ estéril (diluição $10^{-1}$ ). A partir desta primeira diluição $\left(10^{-1}\right)$, foram realizadas diluições sucessivas. Com o auxílio de uma pipeta, retirou-se $1 \mathrm{ml}$ da diluição $10^{-1}$ para adicionar em um tubo de ensaio grande contendo $9 \mathrm{ml}$ de solução salina $\left(10^{-2}\right)$. Este processo se realizou que até atingir a diluição $10^{-5}$, sempre retirando $1 \mathrm{ml}$ da homogeneização anterior.

A determinação de coliformes totais ocorreu pela técnica de tubos múltiplos. Desta forma, $1 \mathrm{ml}$ de cada diluição foi transferido para tubos de ensaio contendo caldo lactosado bile verde brilhante com tubo de Durham invertido, em triplicatas. Após a inoculação, o material foi incubado em estufa bacteriológica a $35^{\circ} \mathrm{C}$ por 24 a 48 horas. $\mathrm{Na}$ presença de resultados positivos para coliformes totais (turvação do meio com bolha de gás no interior do tubo de Durham), foi transferida uma alíquota, com ajuda de alça de semeadura, para o caldo EC, que foi incubado em banho-maria a $45^{\circ} \mathrm{C}$ por 24 a 48 horas para a determinação do NMP de coliformes termotolerantes (BRASIL, 2003).

Após a retirada da unidade analítica (25g) para a obtenção das diluições propostas, a amostra foi congelada a $-17^{\circ} \mathrm{C}$ em refrigerador doméstico, onde permaneceu por quatro semanas. Então, essa amostra foi descongelada sob refrigeração $\left(4^{\circ} \mathrm{C}\right.$ por 24 horas $)$ e a determinação do NMP de coliformes totais e termotolerantes foi repetida. 


\section{RESULTADOS E DISCUSSÃO}

Os resultados obtidos a partir das amostras analisadas estão descritos nas tabelas 1 (amostras recém-adquiridas) e 2 (amostras após sofrerem o congelamento por 28 dias).

Tabela 1 - Número mais provável (NPM) de coliformes totais encontrado em amostras de carne moída recém-adquirida (carne fresca) e após terem sido submetidas a congelamento em freezer doméstico (carne congelada). Ribeirão Preto/SP, 2020.

\begin{tabular}{|c|c|c|}
\hline AMOSTRA & FRESCA (NMP/g) & APÓS CONGELAMENTO (NMP/g) \\
\hline 1 & 230 & 230 \\
\hline 2 & 43000 & 93000 \\
\hline 3 & $<30$ & $<30$ \\
\hline 4 & 93000 & 43000 \\
\hline 5 & $<30$ & 430 \\
\hline 6 & $<30$ & 150 \\
\hline 7 & $<30$ & 74 \\
\hline 8 & 1500 & 930 \\
\hline 9 & $<30$ & $<30$ \\
\hline 10 & 92 & $<3,0$ \\
\hline 11 & 210 & $<3,0$ \\
\hline 12 & 750 & $<3,0$ \\
\hline 13 & 150 & $<3,0$ \\
\hline 14 & 92 & 15 \\
\hline 15 & 4600 & $<3,0$ \\
\hline 16 & 36 & 3,6 \\
\hline 17 & 2400 & 93 \\
\hline 18 & $<30$ & 9,2 \\
\hline 19 & 3,6 & $<3,0$ \\
\hline 20 & 35 & 11 \\
\hline
\end{tabular}

Fonte: Autoria própria 
Tabela 2 - Número mais provável (NPM) de coliformes termotolerantes encontrado em amostras de carne moída recém-adquirida (carne fresca) e após terem sido submetidas a congelamento em freezer doméstico (carne congelada). Ribeirão Preto/SP, 2020.

\begin{tabular}{|c|c|c|}
\hline AMOSTRA & FRESCA (NMP/g) & APÓS CONGELAMENTO (NMP/g) \\
\hline 1 & $<30$ & $<30$ \\
\hline 2 & $<30$ & $<30$ \\
\hline 3 & $<30$ & $<30$ \\
\hline 4 & $<30$ & $<30$ \\
\hline 5 & $<30$ & $<30$ \\
\hline 6 & $<30$ & $<30$ \\
\hline 7 & $<30$ & $<30$ \\
\hline 8 & $<30$ & $<30$ \\
\hline 9 & $<30$ & $<30$ \\
\hline 10 & $<30$ & $<3,0$ \\
\hline 11 & $<30$ & $<3,0$ \\
\hline 12 & $<30$ & $<3,0$ \\
\hline 13 & 36 & $<3,0$ \\
\hline 14 & $<30$ & 3,6 \\
\hline 15 & $<30$ & $<3,0$ \\
\hline 16 & $<30$ & $<3,0$ \\
\hline 17 & $<30$ & $<3,0$ \\
\hline 18 & $<30$ & $<3,0$ \\
\hline 19 & $<3,0$ & $<3,0$ \\
\hline 20 & $<3,0$ & $<3,0$ \\
\hline
\end{tabular}

Fonte: Autoria própria

De acordo com os resultados, há indícios de que o congelamento por 28 dias, seguido do descongelamento por $24 \mathrm{~h}$ em refrigeração não garantem a total paralisação da multiplicação microbiana, visto que as amostras 2, 5, 6, e 7 apresentaram aumento da população de coliformes totais após o processo citado. No entanto as amostras 1, 3 e 9 apresentaram um resultado uniforme no número na população de coliformes totais antes 
e depois do congelamento. Já as amostras 4, 8, 10, 11, 12, 13, 14, 15, 16, 17, 18, 19 e 20 apresentaram uma diminuição na população dos mesmos.

Como é impossível determinar todos os microrganismos que contaminam o alimento devido ao alto custo das análises e à demora em se conseguir todos os resultados, é comum determinar a contagem ou a presença de microrganismos ditos indicadores em alimentos. Esses microrganismos indicam a qualidade higiênico-sanitária do alimento e a provável presença de microrganismos patogênicos, dependendo do indicador pesquisado (JAY, 2000; MONTERO, 2018; LIMA et al., 2021).

$\mathrm{Na}$ análise se alimentos, visando aspectos sanitários, os coliformes são microrganismos que se destacam (FEHLHABER e JANETSCHKE, 1992). Segundo FRANCO (2003), os coliformes totais são um grupo capaz de fermentar a lactose com produção de gás, quando incubados a $36^{\circ} \mathrm{C}$, por 48 horas. Fazem parte desse grupo mais de 20 diferentes gêneros microbianos, incluindo bactérias pertencentes aos gêneros Escherichia, Enterobacter, Citrobacter e Klebsiella. Apenas Escherichia coli tem como hábitat primário o trato intestinal, pois, os outros são encontrados também em outros ambientes como na vegetação e no solo. Os coliformes termotolerantes correspondem aos coliformes totais que apresentam a capacidade de continuar fermentando lactose com produção de gás, quando incubadas a temperaturas de $44-45^{\circ} \mathrm{C}$. São os que mais se aproximam de uma indicação fecal, no entanto, a pesquisa da presença de Escherichia coli é útil quando é desejável determinar se houve contaminação fecal (FRANCO, 2003).

A presença de coliformes termorresistentes nos alimentos indica o contato direto ou indireto com as fezes, pois a Escherichia coli não faz parte da microbiota natural dos produtos, logo as condições sanitárias são insuficientes. As ferramentas usadas para moer carne são excelentes veículos para disseminar essa bactéria (BONACINA et al., 2019; FENELON et al., 2019; SILVA et al., 2019).

Um grande número de bactérias aeróbias mesofílicas e psicrofílicas pode estar relacionado à contaminação alimentar prévia. Esse tipo de contaminação geralmente ocorre durante o processo de abate e no período de transporte e armazenamento do frigorífico, ou seja, na fase de produção e preparação do produto. Devido a isto, é de extrema importância a adoção das boas práticas de fabricação, como cortar e moer carnes, utilizar utensílios esterilizados, limpar o ambiente e manter a higiene dos manipuladores (CIPRIANO et al., 2021). 
Para evitar a multiplicação microbiana e, por consequência, a deterioração da carne, são dispostos tratamentos adequados que afetam essa multiplicação. Dentro dos métodos de conservação de alimentos, destaca-se a refrigeração, que leva a carne a uma temperatura abaixo de $8^{\circ} \mathrm{C}$ esperando que a multiplicação bacteriana seja retardada, principalmente a das bactérias patogênicas. Outro método é o congelamento, que leva o alimento a uma temperatura abaixo de $-10^{\circ} \mathrm{C}$ prevenindo a multiplicação de todos os microrganismos (FORSYTHE, 2013; REZENDE et al., 2020).

Em um trabalho realizado no Piauí, 60 amostras de carne moída foram avaliadas e os autores concluíram que o produto comercializado em Bom Jesus/PI apresenta alterações físico-químicas e elevada contaminação microbiana que comprometem a qualidade e o tempo de vida útil do produto, além de causar riscos à saúde pública (OLIVEIRA et al., 2017).

Em outro trabalho semelhante realizado na Paraíba, Medeiros (2017) concluiu que a carne moída oferecida à população apresentava alta contaminação microbiana, podendo provocar doenças alimentares nos consumidores do produto.

Até o início de 2019, a venda de carne previamente moída por açougues era prática proibida em Ribeirão Preto. Porém, uma lei municipal alterou essa norma e, a partir dela, os açougues estão habilitados a vender a carne já moída. Ressalta-se que o processo de moagem da carne permite uma maior incorporação de oxigênio, o que favorece a aceleração da taxa de reprodução da maioria dos microrganismos presentes. Por outro lado, a ausência de oxigênio retarda a proliferação microbiana e permite maior tempo de vida de prateleira, como observou MENDES et al., (2011).

\section{CONCLUSÃO}

Se realizado de maneira correta, o congelamento pode ser eficiente para diminuir a quantidade de coliforme totais. Entretanto, diversos fatores podem interferir nesse processo, como a qualidade da matéria-prima, a qualidade da higiene dos comércios e todo o processamento que a carne sofre desde o abate do animal até o momento em que chega aos açougues. Além disso, a sanidade e o bem-estar animal também são fatores que podem interferir diretamente na qualidade do produto final. Para evitar contaminações e multiplicação bacteriana, é ideal seguir todas as normas sanitárias exigidas nas legislações vigentes. 


\section{REFERÊNCIAS BIBLIOGRÁFICAS}

ABIEC. Exportações brasileiras de carne bovina. Disponível em

http://www.abiec.com.br/download/estatisticas-mar18.pdf. Acesso em 05/08/2018.

BEZERRA, J. B. et al. Identificação de salmonella spp. na carne bovina moída comercializada em municípios do Vale do Guaribas, no Estado do Piauí. Research, Society And Development, [S.L.], v. 8, n. 12, p. 1-12, 15 out. 2019.

BONACINA, M. S. Avaliação de parâmetros físico-químicos e microbiológicos da carne moída de frango comercializada no município de Erechim, Rio Grande do Sul. Brazilian Journal of Food Research, Campo Mourão, v. 10 n. 2, p. 50-65, 2019.

BRASIL. Ministério da Agricultura, Pecuária e Abastecimento. Instrução Normativa 62, de 26 de agosto de 2003. Oficializa os Métodos Analíticos Oficiais para análises microbiológicas para controle de produtos de origem animal e água. Diário Oficial da União, Seção I, página 14, 18 de setembro de 2003.

CIPRIANO, L. C. et al. Vida útil de carne bovina moída comercializada no Município de Boa Vista - Roraima. Research, Society And Development, [S.L.], v. 10, n. 2, p. 112, 10 fev. 2021.

FEHLHABER, K., JANETSCHKE, P. Higiene veterinária de los alimentos. Zarazoga: Acribia, 1992. 669p.

FENELON et al., A. C. G. Qualidade microbiológica de carne bovina moída comercializada em supermercados na região central de Uberlândia, MG. Revista Brasileira de Higiene e Sanidade Animal, v.13, n.4, p. 452 - 460, 2019.

FORSYTHE, S.J. Microbiologia da segurança dos alimentos. 2ed. Porto Alegre: Artmed, 2013.

FRANCO, B.D.G.M. Microbiologia dos Alimentos. 2ed. São Paulo: Editora Atheneu, 2003.

FRANCO, B. D. G. M.; LANDGRAF, M. Microbiologia dos alimentos. São Paulo: Editora Atheneu, 2008. 93-98 p.

IBGE. Agricultura e Pecuária. Disponível em https://www.ibge.gov.br/estatisticasnovoportal/ economicas/agricultura-e-pecuaria.html Acesso em 05/08/2018.

ICMSF. International Comiission on Microbiological Specifications for Foods. Microrganismos em alimentos 8: utilização de dados para avaliação e controle de processo e aceitação de produto. São Paulo: Blucher, 2015.

JAY, J.M. Modern food Microbiology. 6ed. Maryland: Aspen Publishers, 2000. 679p. 
LIMA, J. A. et al. Análise da qualidade da carne moída comercializada em um município no interior da Paraíba. Research, Society And Development, [S.L.], v. 10, n. 4, p. 1-10, 10 abr. 2021.

MEDEIROS, A.M. Análise dos parâmetros microbiológicos da carne bovina moída "in natura" comercializada na mesorregião do agreste paraibano. Universidade Federal de Paraíba, 2017.

MENDES, R. et al. Effect of CO2 dissolution on the shelf life of ready-to-eat Octopus vulgaris. Innovative Food Science \& Emerging Technologies. v. 12. p. 551- 561. 2011.

MONTEIRO, E. S. et al. Qualidade microbiológica de carne bovina moída comercializada em supermercados do Distrito Federal, Brasil. Revista Brasileira de Higiene e Sanidade Animal, v.12, n.4, p. 520 - 530, 2018.

OLIVEIRA, M.S. et al. Qualidade físico-química e microbiológica da carne moída em açougues. Revista electrónica de Veterinaria, v.18, n.12, 2017.

OLIVEIRA, M. S. et al. Resistência antimicrobiana de Escherichia coli isoladas de carne moída bovina comercializada em Bom Jesus - PI. Revista Agraria Academica, [S.L.], v. 2, n. 5, p. 177-183, 1 set. 2019.

REZENDE, C. L. e et al. COMPARAÇÃO DA QUALIDADE MICROBIOLÓGICA DA CARNE MOÍDA APÓS REPETIDOS PROCESSOS DE CONGELAMENTO E DESCONGELAMENTO / COMPARISON OF THE MICROBIOLOGICAL QUALITY OF GRINDED MEAT AFTER REPEATING FREEZING AND DEFROSTING PROCESSES. Brazilian Journal Of Development, [S.L.], v. 6, n. 12, p. 102681-102690, 2020.

SILVA, D. F. et al. Análise microbiológica da carne bovina moída comercializada em açougues dos mercados de Itapetinga - BA. Research, Society And Development, [S.L.], v. 9, n. 1, p. 1-11, 1 jan. 2020.

SILVA-JÚNIOR, A. C. et al. Análises microbiológicas de carne bovina moída comercializada em supermercados. Pubvet, [S.L.], v. 12, n. 10, p. 1-7, out. 2018.

TEIXEIRA, D. A. et al. INQUÉRITO MICROBIOLÓGICO E POSSÍVEIS CONTAMINAÇÕES ASSOCIADAS AOS PROCEDIMENTOS DE MANIPULAÇÃO DE CARNES COMERCIALIZADAS EM AÇOUGUES DE TEÓFILO OTONI-MG. Revista Multidisciplinar do Nordeste Mineiro, Teófilo Otoni, v. 1, n. 1, p. 285-299, jun. 2017.

Recebido em: 01/11/2021

Aprovado em: 30/11/2021

Publicado em: 03/12/2021 